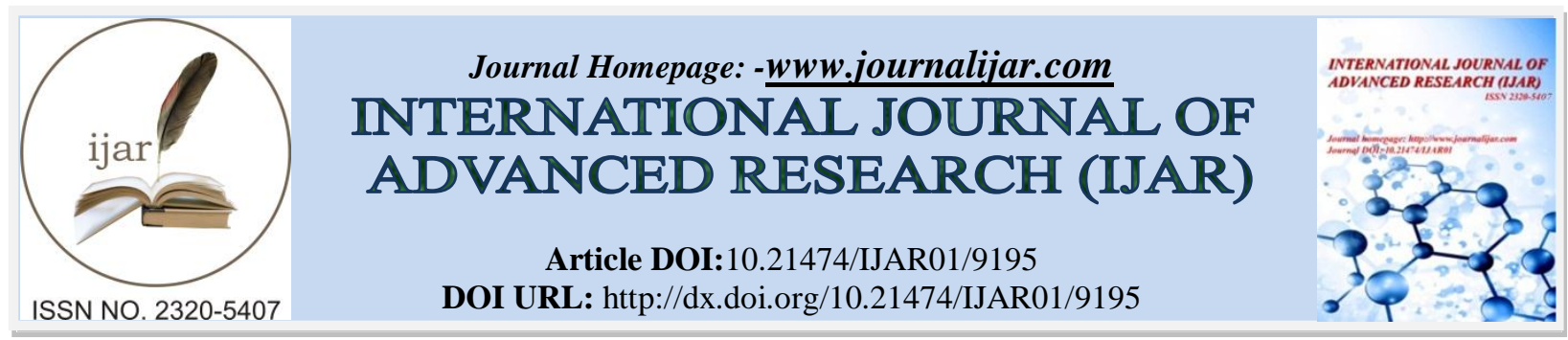

RESEARCH ARTICLE

\title{
SEM ANALYSIS OF NONMETALLIC INCLUSION OF THE STAINLESS STEEL MODIFIED WITH ADDITION OF Zr AND Te
}

\author{
Dr. Sc. Derviš Mujagić ${ }^{1}$, Dr. Sc. Aida Imamović ${ }^{2}$ And Dr. Sc. Mirsada Oruč². \\ 1. University of Zenica, Institute "Kemal Kapetanović" \\ 2. University of Zenica, Faculty of Metallurgy and Technology.
}

\section{Manuscript Info}

Manuscript History

Received: 02 April 2019

Final Accepted: 04 May 2019

Published: June 2019

\section{Key words:-}

stainless steel, Thermo-Calc, alloying, non-metallic inclusions, testing on SEM

\begin{abstract}
Control of the formation of nonmetallic inclusions and their characterization is the foundation for improving the qualities of steel products, as well as designing new types of steel.

In order to produce steel with improved machinability, such as austenitic stainless steel $\mathrm{X} 8 \mathrm{CrNiS18-9}$, is made modification of the chemical composition of nonmetallic inclusions. In this paper, ThermoCalc phase calculation and SEM studies of the presence and type of inclusions in austenitic stainless steel with the addition of sulphur of the label X8CrNiS18-9 with and without addition of alloying elements $\mathrm{Zr}$ and $\mathrm{Te}$, were carried out individually in order to investigate their influence on the shape and chemical composition of the inclusions.
\end{abstract}

Copy Right, IJAR, 2019,. All rights reserved.

\section{Introduction}

The research was carried out on an austenitic stainless steel labelled $\mathrm{X} 8 \mathrm{CrNiS} 18-9$, as defined in standard EN 10088-3: 2005, which was produced at semi-industrial plants at the Institute "Kemal Kapetanović", University of Zenica, in order to determine the influence of zirconium and tellurium in austenitic stainless steel [1].

Grade $\mathrm{X} 8 \mathrm{CrNiS} 18-9$ is the most readily machinable of all the austenitic grades of stainless steel. The machinable nature of grade $\mathrm{X} 8 \mathrm{CrNiS18-9}$ is due to the presence of sulphur in the steel composition. The X8CrNiS18-9 stainless steel referred to as "free-machining" stainless steel has the following nominal chemical composition, table 1 [2-5].

Table 1. Nominal chemical composition of standard X8CrNiS18-9 austenitic stainless steel, wt \%

\begin{tabular}{|c|c|c|c|c|c|c|}
\hline $\mathbf{C}$ & $\mathbf{M n}$ & $\mathbf{S i}$ & $\mathbf{C r}$ & $\mathbf{N i}$ & $\mathbf{P}$ & $\mathbf{S}$ \\
\hline 0.15 & 2.00 & 1.00 & $17.0-19.0$ & $8.0-10.0$ & 0.2 & $0.15 \mathrm{~min}$ \\
\hline
\end{tabular}

The manganese sulphide $(\mathrm{MnS})$ stringers help to promote the easy breakup of metal shavings during machining. Whilst the sulphur improves machining, it also causes a decrease in the corrosion resistance and a slight lowering of the toughness and general decrease of the mechanical properties.

The intention is to make higher machinability of this steel grade but with good mechanical properties. The results show that after microalloying by tellurium or zirconium the modification of nonmetalic inclusion - manganese sulphide of X8CrNiS18-9 stainless steel can be significantly changed. The machinability varies with the inclusion shape, which means that it is desirable that the manganese sulphide inclusions in steel must be as spherical as possible [6]. 
The aim of the research was to examine the possibility of reducing the effect of Te and $\mathrm{Zr}$ on the mechanical properties of X8CrNiS18-9 by microalloying by tellurium and zirconium, which can modify the MnS and improve machinability, with mechanical properties in the limits prescribed for X8CrNiS18-9 standard grade.

\section{Experimental work}

Detrimental effects of inclusions in steel do not only depend on their sizes, shape, distribution, but also on their chemical composition and mechanical properties. For this reason, the control of formation of nonmetallic inclusion and the characterization present the basis of improvement of steel product properties and lead to sustainable development in design of new steel grades. Thermo-Calc software package is used to show the temperature region where in theoretical way it is possible to form non metallic inclusions. Also it have to take into consideration that Thermo-Calc calculation is related to equilibrium state and is also related to chemical steel composition, in this case of standard X8CrNiS18-9.

The aim of the research was to examine the possibility of increasing the effect of machinability of X8CrNiS18-9 stainless steel microalloying by tellurium and zirconium. They seem to exert beneficial effects by promoting the retention of globular-shaped sulphide type inclusions.

The intention is to make better machinability of X8CrNiS18-9 stainless steel but to keep good mechanical properties. Tellurium or zirconium are considered to have a less deleterious effect than sulphur on mechanical properties [7].

\section{Results and discussion}

Thermo-calc calculation

Thermo-Calc calculation of characteristically equilibrium phases for standard X8CrNiS18-9 depending on temperature is shown that characteristically nonmetallic inclusions in these steels are MnS types by which precipitation starts under liquids temperature, figure 1 [6].

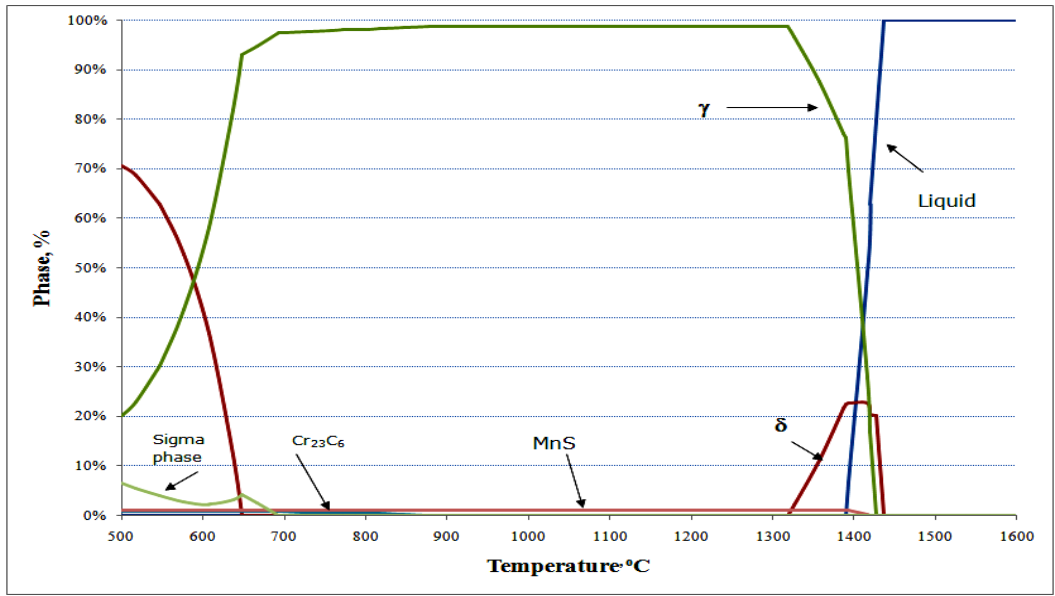

Figure 1: Thermo-Calc calculation of characteristically equilibrium phases for standard X8CrNiS18-9 depending on temperature [6]

\section{Analysis of nonmetallic inclusions}

In accordance with the program of testing at the Department for melting and casting metals of the Institute "Kemal Kapetanović", several melt of different chemical composition was made [8]. Production of X8CrNiS18-9 stainless steel microalloyed by tellurium and zirconium was performed in a vacuum induction furnace with capacity of $20 \mathrm{~kg}$ at the Institute "Kemal Kapetanović" in Zenica. The ingots were processed by forging, hot rolling and heat treatment.

The first melt was made without the addition of alloying elements, while in the remaining melts, the various contents of zirconium and tellurium were added individually. In this paper, the tests were performed for three variants (three different melts), with the mentioned alloying elements being added within the boundaries according 
to the literature [8]. The samples from variant 1 (excluding alloying elements) were tested, followed by variants 2 with the addition of $\mathrm{Zr}$, and variant 3 with the addition of Te table 2 [8].

Table 2. Chemical composition of modified X8CrNiS18-9 austenitic stainless steels, wt. \%

\begin{tabular}{|c|c|c|c|c|c|c|c|c|c|c|}
\hline $\begin{array}{c}\text { Type of } \\
\text { X8CrNiS18-9 }\end{array}$ & No. of variant & $\mathbf{C}$ & $\mathbf{S i}$ & $\mathbf{M n}$ & $\mathbf{P}$ & $\mathbf{S}$ & $\mathbf{C r}$ & $\mathbf{N i}$ & $\mathbf{Z r}$ & $\mathbf{T e}$ \\
\hline Basic type & Variant 1 & 0.03 & 0.42 & 0.61 & 0.021 & 0.18 & 18.3 & 9.4 & - & - \\
\hline by Zr & Variant 2 & 0.04 & 0.35 & 0.75 & 0.021 & 0.17 & 18.8 & 9.4 & 0.016 & - \\
\hline by Te & Variant 3 & 0.05 & 0.40 & 0.80 & 0.010 & 0.16 & 18.9 & 9.3 & - & 0.033 \\
\hline
\end{tabular}

In order to prepare a sample, grinding and polishing of the testing samples was carried out. Than the analysis of the content, size and distribution of non-metallic inclusions in non-etched state was carried out at the Institute of Zenica, Bosnia and Herzegovina. For each of the above samples, line and point analysis were done, and also mapping [1,8]. The detailed SEM/EDS analyses of modified nonmetallic inclusions were performed by scanning electron microscope (SEM) Jeol JSM 5610 with attached energy-dispersive x-ray spectroscopy (EDS) system. Examination of the inclusions on the scanning electron microscope gives the highest data on the type of inclusions and their composition. Figure 2 shows a linear analysis of characteristic non-metallic inclusions for a sample of austenitic stainless steel X8CrNiS18-9 without additives of alloying elements (variant 1).

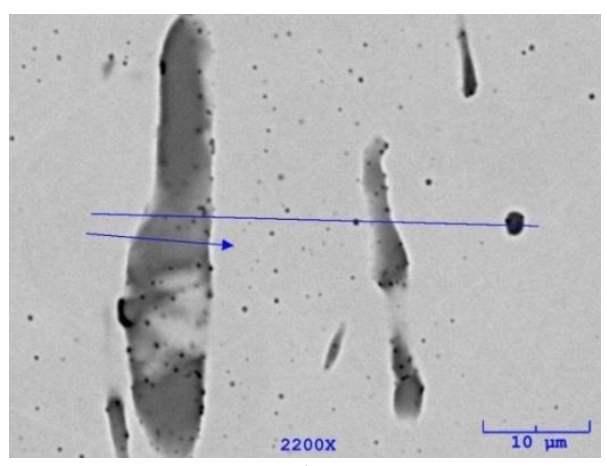

a)

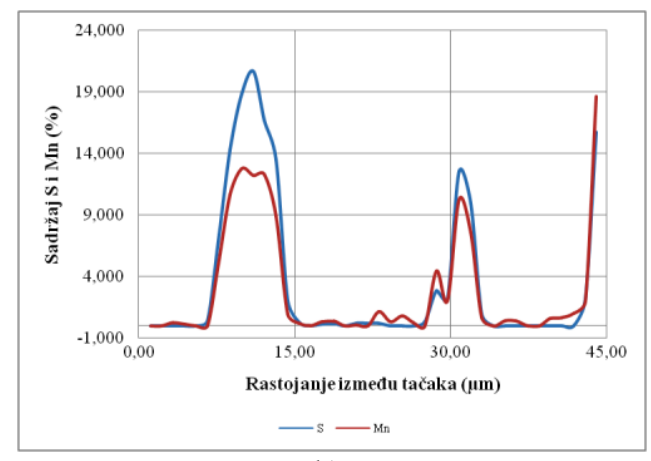

b)

Figure 2: Linear analysis of the sample without additives of alloying elements (variant 1):

a) SEM image; b) a distribution diagram of S and Mn [8]

The shape and composition of inclusions in the standard X8CrNiS18-9 grade are typical MnS stringers, [8].

Figure 2, i.e. the distribution diagram of the contents of $S$ and $\mathrm{Mn}$ in the line shown (Figure $2 \mathrm{~b}$ ), shows how the inclusions are given in the SEM picture (Figure 2a), in its chemical composition predominantly manganese sulphides [8].

Figure 3 gives a mapping showing where each of the elements represented by mapping is in relation to the SEM image, showing the inclusions of the sample without the addition of alloying elements (variant 1) [8].

It is clear from the picture that the inclusions from the SEM image (Figure 3a) are almost identical to those in the images showing the position of manganese and sulphur (Figures $3 \mathrm{~b}$ and $3 \mathrm{c}$ ), whereas the black prints of these inclusions in the image showing the distribution of iron, in fact, denote the impoverishment of iron of the mentioned areas (Figure 3d). 


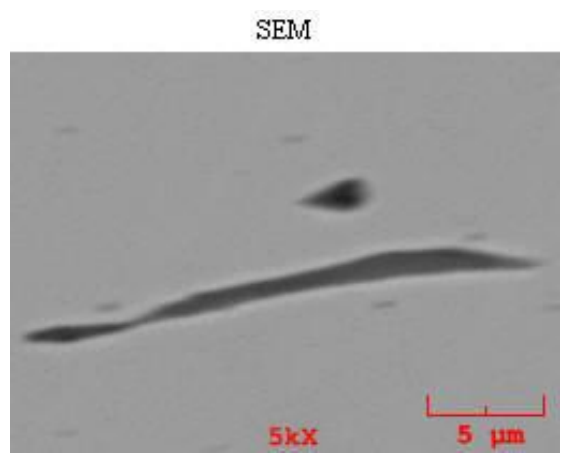

a)

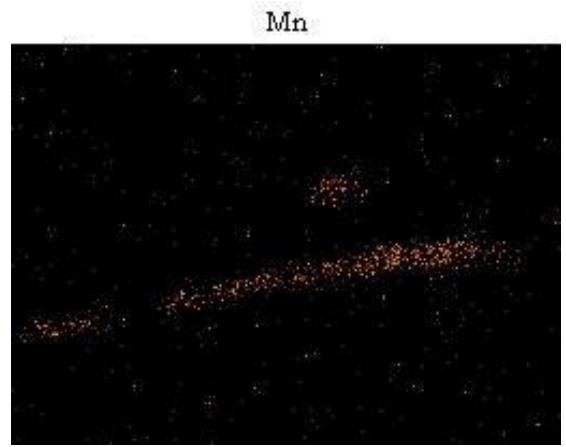

c)

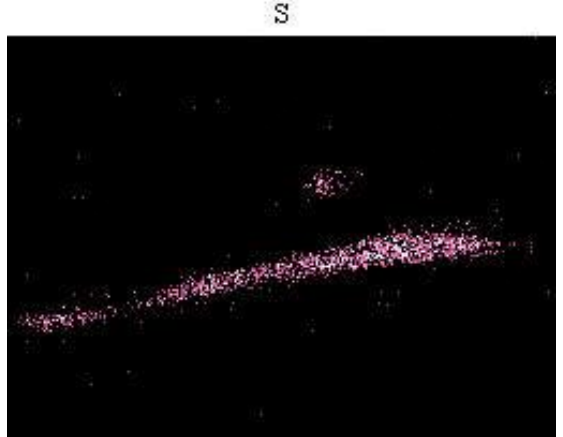

b)

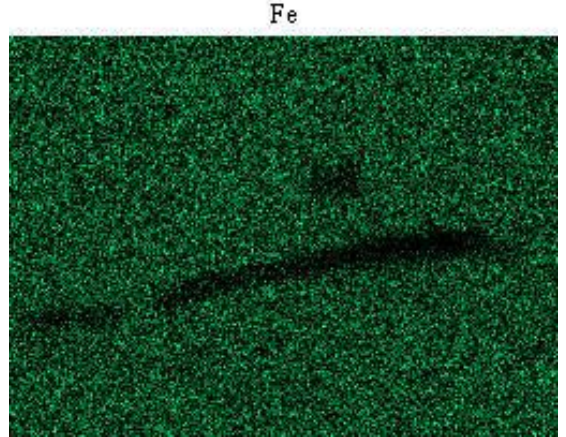

d)

Figure 3: Mapping of the sample without additions of alloying elements (variant 1):

a) SEM image; b) - d) the elements S, Mn and Fe [8]

Figure 4 shows a linear analysis of the zirconium supplement (variant 2). Figure 4, i.e. the distribution diagram of the contents of S, Mn and $\mathrm{Zr}$ in the line (Figure 4b) shows how the inclusions are presented in the SEM figure (Fig. 4a), not only involving manganese sulphides, but complex inclusions, which contain a certain amount of zirconium. The figures also show, and the diagram confirms that the zirconium is within the inclusions of manganese sulphide, as their integral part [8].

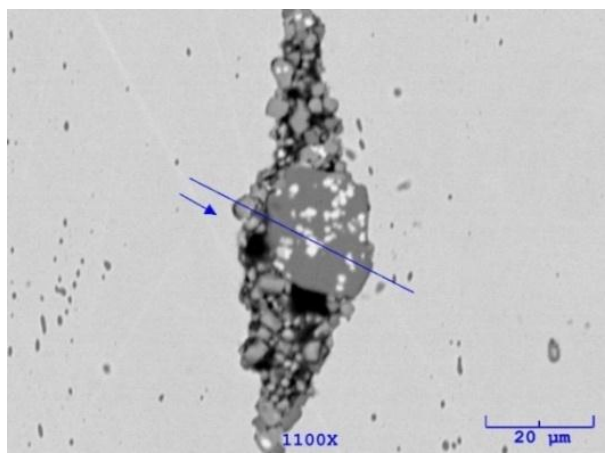

a)

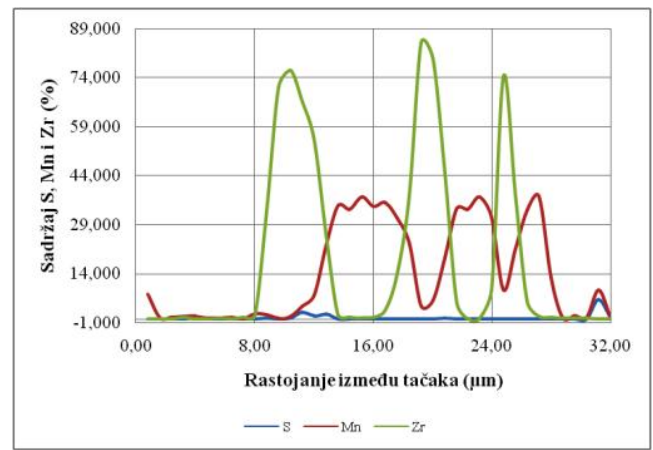

b)

Figure 4: Line analysis of the zirconium supplement (variant 2): a) SEM image;

b) the distribution diagram of $\mathrm{S}, \mathrm{Mn}$ and $\mathrm{Zr}$ [8]

In the figure 5 is shown a mapping where each of the represented elements is in relation to the SEM image, showing the inclusions of the sample with the addition of zirconium (variant 2) [8]. It is clear from the picture that the inclusions from the SEM image (Figure 5a) are almost identical to those in the images showing the position of the manganese and sulphur (Figures 5b and 5c). Also, on the basis of the comparison of the SEM image with an image indicating the zirconium distribution, it can be clearly concluded that the zirconium is at its maximum in two different locations within the two different inclusion (Figure 5d). 


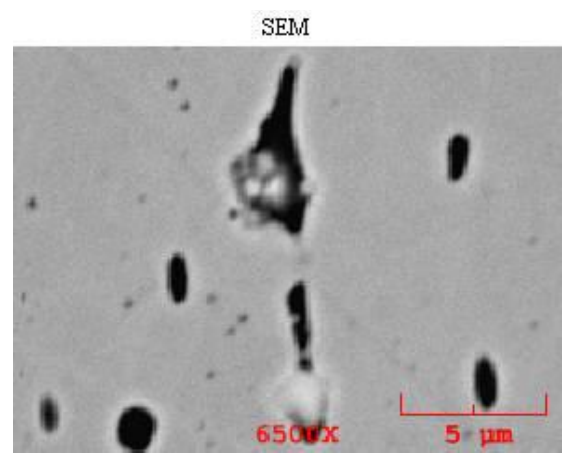

a)

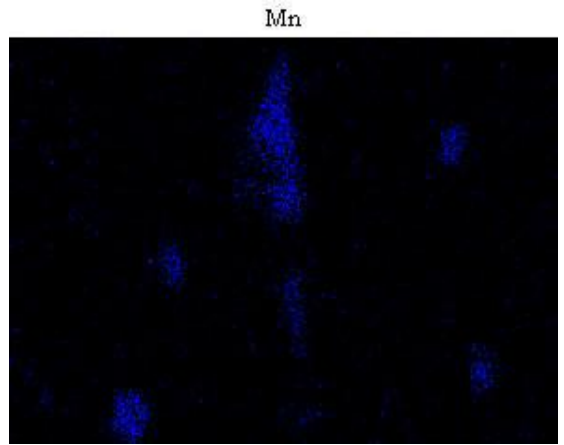

c)

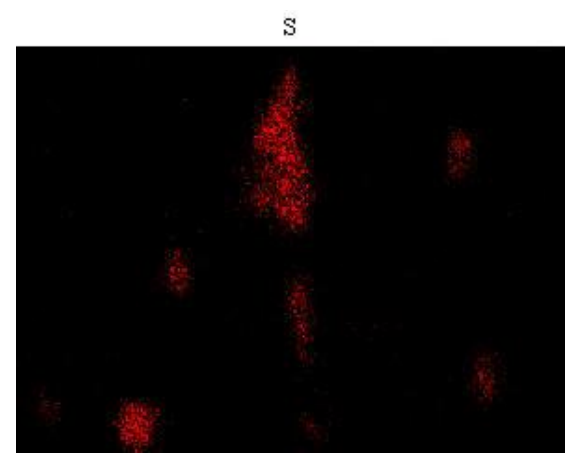

b)

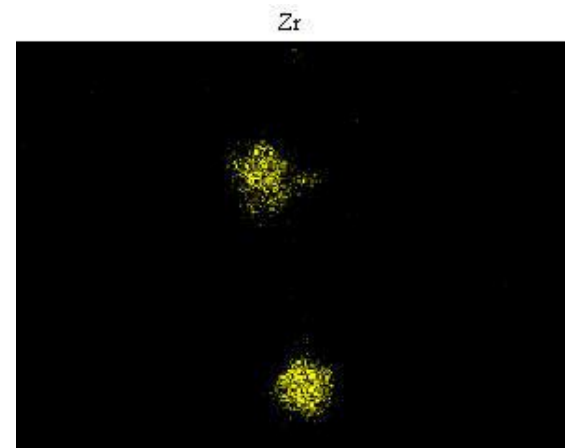

d)

Figure 5: Mapping a sample with the addition of zirconium (variant 2): a) SEM image; b) - d) S, Mn, and Zr elements [8]

Figure 6 gives a linear analysis of the pattern with the addition of tellurium (variant 3) [8]. Figure 6, i.e. the distribution diagram of the contents of S, Mn and Te shows that the inclusion shown in the SEM figure (Fig. 6a), in addition to the already conventional manganese sulphide, contains to a certain extent tellurium. The picture also shows, and the diagram confirms that the tellurium practically surrounds the inclusion of manganese sulphide, and is located at its ends.

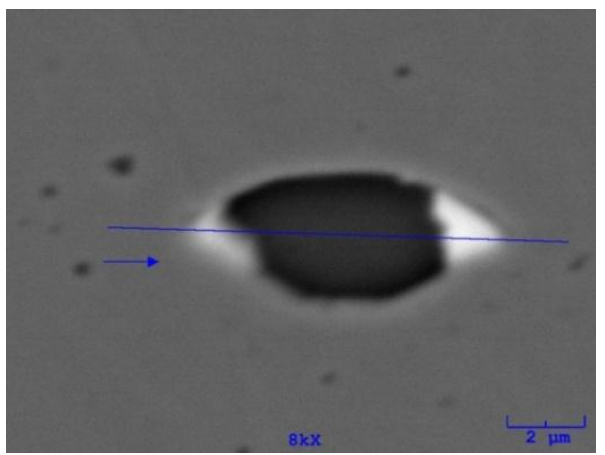

a)

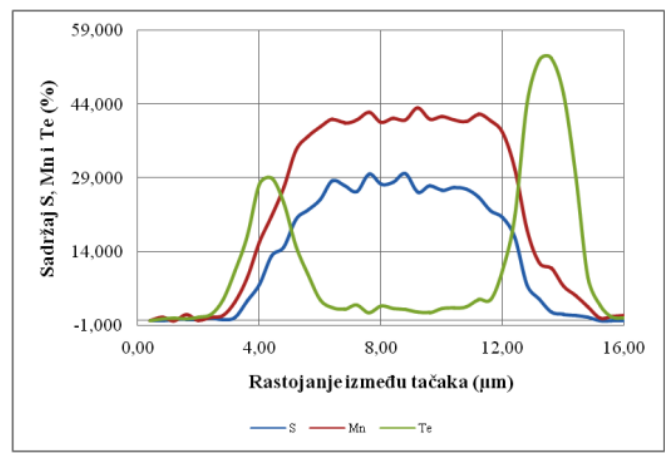

b)

Figure 6: Line analysis of the sample with the addition of tellurium (variant 3):a) SEM image; b) distribution diagram of S, Mn and Te according to the displayed line [8]

Figure 7 shows a mapping where each of the elements represented by mapping is in relation to the SEM image, which shows the inclusions of the sample with the addition of tellurium (variant 3) [8]. It is clear from the picture that the inclusions from the SEM image (Figure 7a) are almost identical to those in the images showing the position of sulphur and manganese (Figures $7 \mathrm{~b}$ and $7 \mathrm{c}$ ). From figure $7 \mathrm{~d}$ it can be clearly concluded that, as already mentioned above, the tellurium is surrounds the inclusion of manganese sulphide, and is located at its ends.

The steel - variant 3 with the addition of tellurium has characteristically manganese sulphides combined with a tellurium which are a typical globular shape and specifically improve the machinability of this steel. 


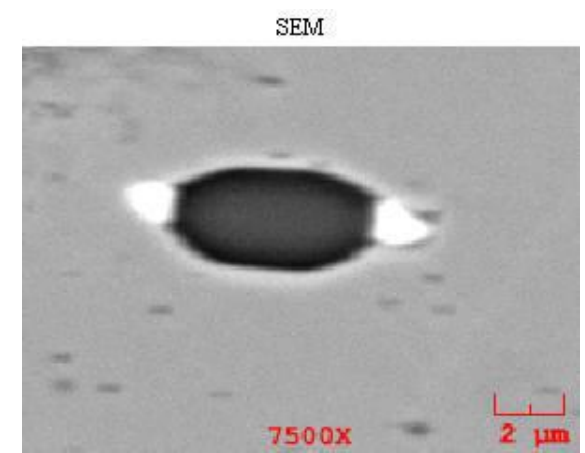

a)

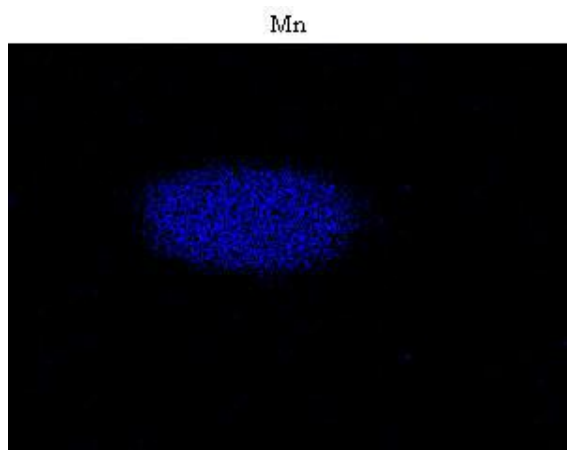

c)

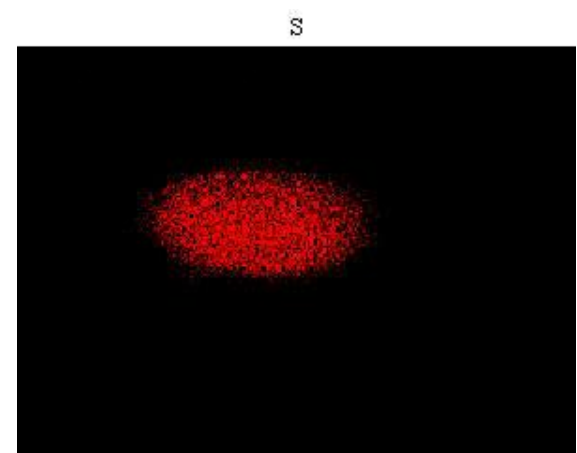

b)

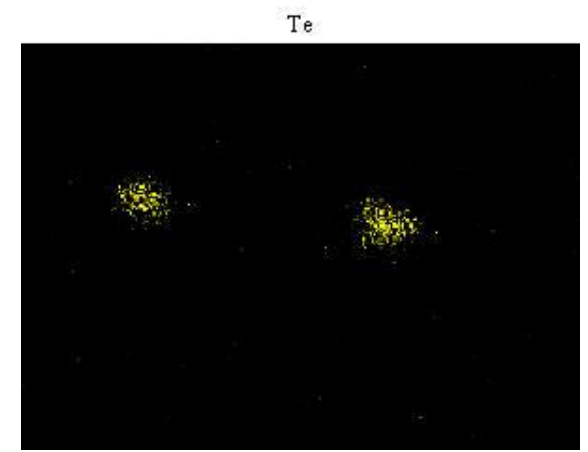

d)

Figure 7: Mapping a sample with addition of tellurium (variant 3): a) SEM image;

b) - d) S, Mn, S and Te elements [8]

\section{Conclusions:}

Detrimental effects of inclusions in steel do not only depend on their sizes, shape, distribution, but also on their chemical composition and mechanical properties. The aim of the research was to determine the effects of zirconium and tellurium on types of non-metallic inclusions in austenitic stainless steel X8CrNiS18-9.

Thermo-Calc calculation of characteristically equilibrium phases is shown that characteristically nonmetallic inclusions in these steels are manganese sulphides types.

Metallographic tests on the SEM were performed and the influence of the chemical elements of the zirconium and the tellurium on the change in the type and chemical composition of non-metallic inclusions was monitored.

It has been found that the basic types of inclusions in this steel are manganese sulphides and that the nonmetallic inclusions of austenitic stainless steel X8CrNiS18-9 can be modified by addition of zirconium and tellurium. Especially nonmetallic inclusions of manganese sulphides types in combination with a tellurium can be translated into a suitable form, and on one side they will provide good machinability and, on the other hand, will not adversely affect the properties of austenitic stainless steel X8CrNiS18-9.

\section{Reference:-}

1. D.Mujagić, A. Imamović, M. Oruč, S.Muhamedagić: Analysis of the type and chemical content of the inclusion on sem of the stainless steel with and without the addition of $\mathrm{Zr}$ and Te: 4th International Conference „NEW TECHNOLOGIES NT-2018“ Development and Application, Sarajevo, 14-16. June 2018, 72-79.

2. J. Grum: Quantitative analysis of sulphide inclusions in free cutting steels and their influence on machinability, Acta Stereol, Ljubljana, (1999), Vol. 18, No. 3, pp. 319-331

3. H. Shibata, T. Tanaka, K. Kimura, S.-Y. Kitamura: Composition change in oxide inclusions of stainless steel by heat treatment, Ironmaking and Steelmaking Vol. 37 No. 7, (2010) 
4. J.R. Davis: Alloying Understanding The Basics, ASM International, Materials Park, Ohio, USA, 2001; pp, 255 259.

5. D. Senk: Steel metallurgy - challenged by materials, Stahl und Eisen 134 (2014) No. 11, pp. 110-121;

6. Mahmutović, A. Nagode, M. Rimac, D. Mujagić: Modification of inclusions in austenitic stainless steel by adding tellurium and zirconium, Materials and Technology 3, ISSN:1580-2949, MTAE9, 51 (3), 2017. 523-528.

7. M. Oruč, R. Sunulahpašić - "Contemporary metal materials" - University of Zenica, Faculty of Metallurgy and Technology, Zenica, 2005

8. D. Mujagić: "Contribution to research of influence microalloying with boron, zirconium and tellurium on properties of austenitic stainless steel with sulphur addition X8CrNiS18-9", PhD thesis, University of Zenica, Faculty of Metallurgy and Technology, Zenica, January 2017 